\title{
Common psychocutaneous disorders in children
}

This article was published in the following Dove Press journal:

Neuropsychiatric Disease and Treatment

9 February 2015

Number of times this article has been viewed

\section{Anca Chiriac ${ }^{1-3}$ \\ Piotr Brzezinski ${ }^{4}$ \\ Tudor Pinteala ${ }^{5}$ \\ Anca E Chiriac ${ }^{5}$ \\ Liliana Foia ${ }^{5}$}

'Apollonia University, Department of Dermato-Physiology, ${ }^{2}$ Nicolina Medical Center, Department of Dermatology,

3"P. Poni" Institute of Macromolecular Chemistry, lași, Romania; ${ }^{4}$ Department of Dermatology, Sixth Military Support Unit, Ustka, Poland; ${ }^{5} \mathrm{Gr} T$ Popa University of Medicine and Pharmacy, lași, Romania
Correspondence: Anca Chiriac Apollonia University, Nicolina Medical Center, Department of Dermatology, "P Poni" Institute of Macromolecular Chemistry, Strada Muzicii nr2, lași, Romania

Tel +40 721234999

Email ancachiriac@yahoo.com
Abstract: The prevalence of psychosomatic disorders among dermatological patients is high but frequently unreported because of difficulties in diagnosing and treating this patient group. Psychiatric and psychological factors may play different roles in the pathogenic mechanism of some skin diseases. The mainstay of diagnosis and treatment is the differentiation between skin disorders associated with psychiatric illness and those of a purely psychiatric nature. Dermatologists and psychiatrists should be aware of this pathology and work together as a team to resolve difficult cases, especially in children. The present paper highlights the psychocutaneous diseases most frequently seen by dermatologists in pediatric population.

Keywords: psychosomatic disorders, factitial dermatitis, psychodermatology

\section{Introduction}

Current knowledge about the multiple and various facets of psychodermatology is of significant importance. Psychocutaneous disorders are classified using the following system: $:^{1,2}$

\section{Dermatoses of primary psychiatric disorders}

- Dermatitis artefacta

- Dermatitis para artefacta: skin picking syndrome (epidermotillomania, neurotic excoriations); acne excoriata; pseudoknuckle pads; morsicatio buccarum; factitious cheilitis; onychophagia; onychotillomania, onychotemnomania; trichotillomania, trichotemnomania, trichoteiromania

- Delusions of parasitosis

- Somatoform disorders (glossodynia)

- Body dysmorphic disorders (dysmorphophobia).

\section{Psychosomatic diseases (dermatoses with a multifactorial basis and a psychiatric component)}

- Psoriasis

- Atopic dermatitis

- Acne excoriata

- Chronic forms of urticaria

- Lichen simplex chronicus

- Hyperhidrosis.

\section{Psychosomatic diseases}

These are secondary psychiatric disorders due to disfiguring dermatoses and are associated with depression, anxiety, and delusional symptoms. 


\section{Diagnosis}

In daily pediatric dermatology, some of the above skin lesions are more frequently diagnosed. Clinicians caring for children should be able to recognize the following common factitial dermatoses and know when to ask for psychiatric intervention.

\section{Dermatitis artefacta}

Dermatitis artefacta (also known as factitial dermatitis or pathomimia) is characterized by self-inflicted skin lesions that raise suspicion because of their curious morphology, localization, lack of therapeutic response, and long evolution (Figures 1 and 2). The highest prevalence of dermatitis artefacta is between adolescence and early adulthood, ${ }^{3}$ and the condition is seldom reported in small children.

It is very important to differentiate dermatitis artefacta, where self-inflicted injuries are unconscious, from:

- dermatitis para artefacta, with semiconscious/admitted self-induced lesions

- malingering with induced and simulated disorders for the purpose of material gain

- special forms, such as Gardner Diamond syndrome, Münchausen syndrome, and Münchausen-by-Proxy syndrome. ${ }^{4}$

\section{Dermatitis para artefacta} Skin picking syndrome

This entity has been described in the medical literature under various synonyms, ie, epidermotillomania, neurotic excoriations, emotional excoriations, nervous scratching artifact, dermatillomania, and para-artificial excoriations (Figure 3).

\section{Acne excoriata}

Acne excoriata is considered by several authors to be the same entity as skin picking syndrome, ${ }^{2}$ although there is

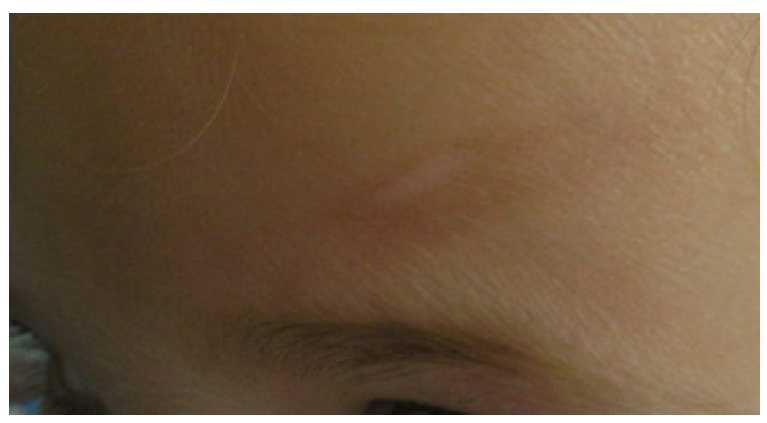

Figure I Skin lesion on the frontal area of the face, mechanically induced by a toy, in a 4-year-old girl.

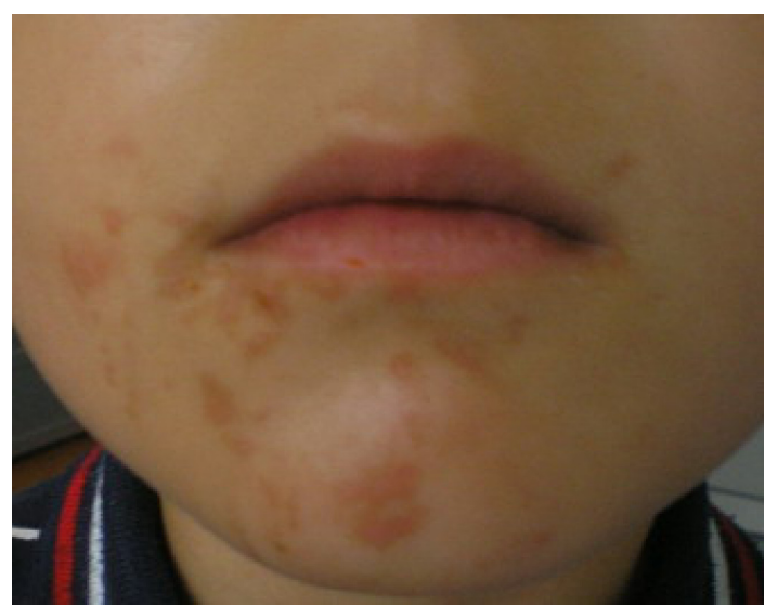

Figure 2 Pigmented post-inflammatory lesions on the chin of a small boy, induced by continuously rubbing the area with marker pens.

ongoing discussion with regards to the identification of these entities (Figure 4).

\section{Neurotic excoriations}

Neurotic excoriations are seen in patients with impaired impulse control and more frequently observed in females, although cases in children have been reported. The skin lesions result from self-injury in order to reduce emotional tension. The prevalence is not known, although it is estimated that $2 \%$ of dermatology patients suffer from this disease. ${ }^{5}$

The clinical picture is quite characteristic, with excoriations and superficial erosions, sometimes covered by crusts, scars, and hyperpigmentation, and most often produced by a sharp instrument. Cutaneous lesions result from the intense impulse of harming the skin.

Psychiatric examination and treatment is mandatory because neurotic excoriations can be the first sign of an extensive list of psychiatric disorders, including depression,

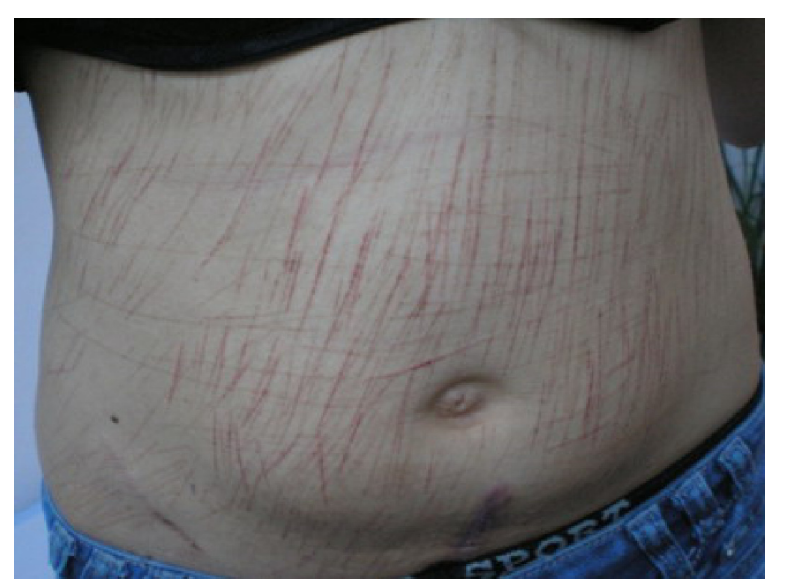

Figure 3 Self-induced cutaneous lesions on a 14-year-old girls stomach inflicted by a sharp pencil. 


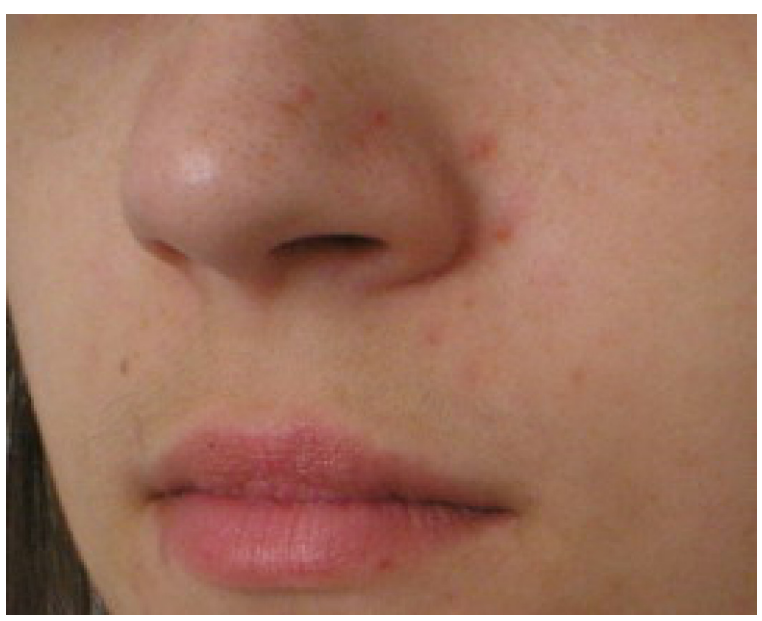

Figure 4 Acne excoriata (self-induced lesions on the face using a magnifying mirror).

anxiety, body obsessive-compulsive disorder, body dysmorphic disorder, borderline personality disorder, and hypochondriasis. ${ }^{6}$ It is very important for the child that family members accept the psychiatric nature of this skin disease and undertake psychiatric treatment.

\section{Trichotillomania, trichotemnomania, trichoteiromania}

From the dermatology point of view, trichotillomania is a nonscarring alopecia induced by repetitive self-pulling of the hair. On clinical examination, different hair lengths are noticed, with broken hairs, new growth, no desquamation, and a negative pull test (Figure 5).

Psychiatric criteria include existence of nervousness associated with pulling the hair, and relief afterward as a result of reducing tension, depression, and anger. Trichotillomania should be differentiated from obsessive-compulsive disorder

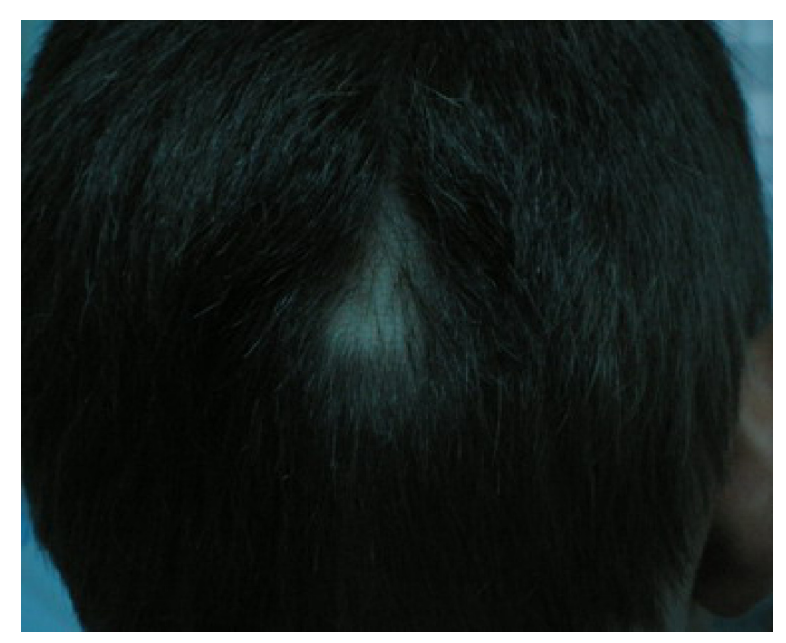

Figure 5 Trichotillomania in an 8-year-old boy. where pulling the hair is an obsessive impulse. It commonly affects the scalp, but other hairy regions can be affected, including the eyebrows, eyelashes, and even the pubic hair. In small children, trichotillomania is mainly diagnosed on the scalp. ${ }^{5}$ In trichotemnomania, the hair is intentionally cut off, so the disorder is part of a malingering syndrome. Trichoteiromania is characterized by breaking the hairs by rubbing or scratching the scalp in a repetitive way.

\section{Pseudoknuckle pads}

Pseudoknuckle pads are hypertrophic lesions localized to the dorsal aspects of the finger joints, more often unilaterally, caused by habitual chewing, rubbing, or sucking the fingers (Figure 6), and is the expression of a psychiatric disorder, eg, mental retardation, bulimia nervosa (self-induced vomiting in girls), or obsessive behavior.

\section{Factitious cheilitis}

Factitious cheilitis is a common observation in pediatric dermatology patients with compulsive disorders. The main mechanism is licking the lips, with or without biting, followed by development of an irritant contact dermatitis and a characteristic clinical picture (Figure 7A-C).

\section{Onychophagia, onychotillomania, onychotemnomania}

Onychophagia is nail biting or chewing with swallowing of nail fragments, and is often diagnosed in children. In small children, onychophagia can be associated with thumb-sucking

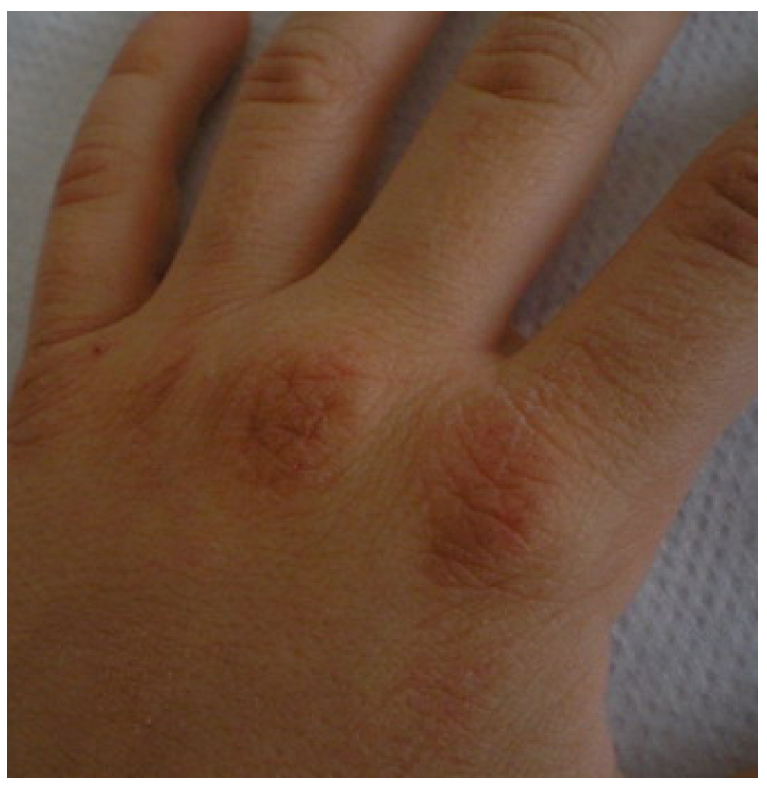

Figure 6 Pseudoknuckle pads on the left hand of an II-year-boy with severe mental retardation. 

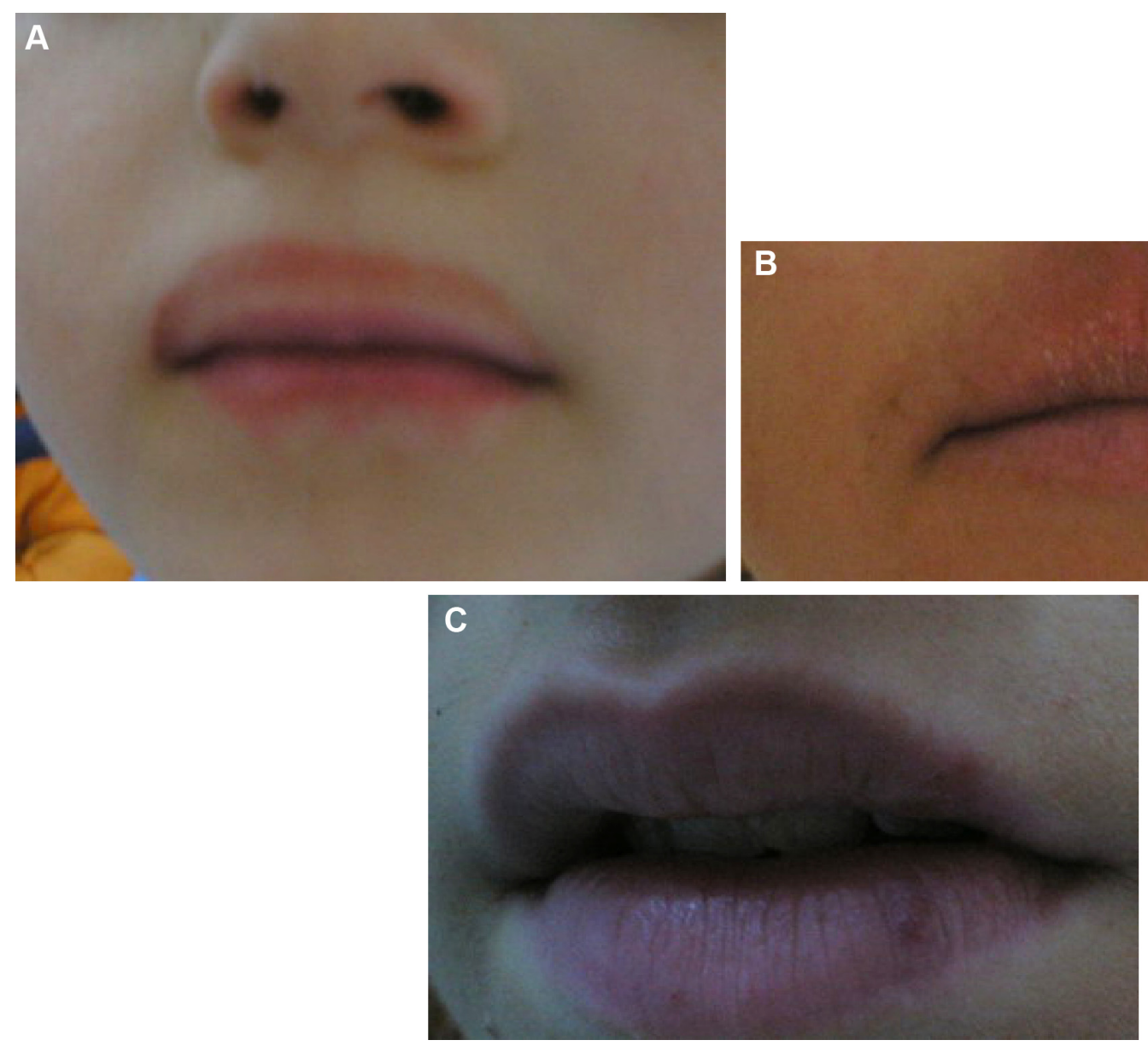

Figure 7 (A) Lip-lickers dermatitis in a 4-year-old boy. (B) Cheilitis artefacta in a 14-year-old girl with secondary eczematization. (C) Small ulcerations on the lower lip of an 8 -year-old girl, self-induced by biting.

or secondary irritant dermatitis, infection, inflammation, and even malformation of the digits. It results from stressful situations and does not require a psychiatric evaluation in all situations. Onychotillomania refers to a self-induced nail disease brought on by chronic traumatization of the nail, also involving the paronychia and cuticle, with a variable degree of severity (Figure 8). Onychotemnomania is the result of cutting the nails too short, with secondary trauma to the nails.

\section{Management}

Psychodermatology is an expression of the interaction between skin and mind. It is of paramount importance for the clinician to establish an appropriate physician-patient-family relationship in order to diagnose and treat factitial skin diseases. Clues to the clinical diagnosis include bizarre, linear, or geometric features on accessible parts of the body, ambiguous history of lesions that are done by the patient for public eye. Skin injuries can be found on locations easily accessible for self-injury, ie, the face, trunk, and extremities.

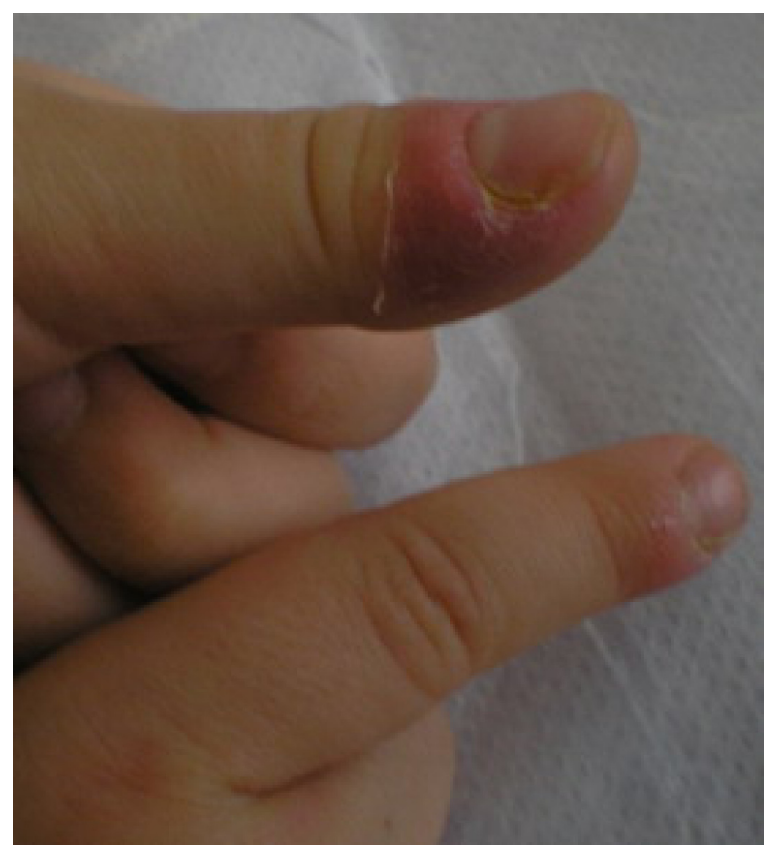

Figure 8 Onychophagia affecting the right hand and onychotillomania affecting the left thumb. 
Skin lesions "call for attention" and highlight an autoaggressive behavior induced by depression, anxiety, and compulsive disorders. Moreover, the patient denies having produced the lesions, and family members, particularly parents, may seek multiple medical consultations before accepting the diagnosis of dermatitis artefacta and the need for psychiatric assessment. Team work between dermatology and psychiatry is the most important step in long and very difficult road of treatment for psychocutaneous disorders in children.

There are no national data regarding the occurrence of these disorders in children; this is a report made by dermatologists based on clinical information. This paper seeks to draw attention to the distinctive aspects of skin lesions induced by psychiatric disorders and to emphasize the importance of an interdisciplinary approach. With close collaboration between dermatologists, psychiatrists, and pediatricians, a national or international report could be done in the future.

\section{Disclosure}

The authors report no conflicts of interest in this work.

\section{References}

1. Harth W, Gieler U, Kusnir D, Tausk FA. Clinical Management in Psychodermatology. Heidelberg, Germany: Springer-Verlag; 2008.

2. Al Hawsawi K, Pope E. Pediatric psychocutaneous disorders: a review of primary psychiatric disorders with dermatologic manifestations. Am J Clin Dermatol. 2011;12(4):247-257.

3. Harth W, Taube KM, Gieler U. Facticious disorders in dermatology. J Dtsch Dermatol Ges. 2010;8(5):361-372.

4. Koblenzer CS. Psychiatric syndromes of interest to dermatologists. Int J Dermatol. 1993;32(2):82-88.

5. Heller MM, Koo JM. Neurotic excoriations, acne excoriee and factitial dermatitis. In: Heller MM, Koo JY, editors. Contemporary Diagnosis and Management in Psychodermatology. 1st ed. Newton, PA, USA: Handbooks in Health Care Co; 2011.

6. Koo J. Psychodermatology: a practical manual for clinicians. Curr Probl Dermatol. 2005;7(6):204-232.
Neuropsychiatric Disease and Treatment

\section{Publish your work in this journal}

Neuropsychiatric Disease and Treatment is an international, peerreviewed journal of clinical therapeutics and pharmacology focusing on concise rapid reporting of clinical or pre-clinical studies on a range of neuropsychiatric and neurological disorders. This journal is indexed on PubMed Central, the 'PsycINFO' database and CAS,

\section{Dovepress}

and is the official journal of The International Neuropsychiatric Association (INA). The manuscript management system is completely online and includes a very quick and fair peer-review system, which is all easy to use. Visit http://www.dovepress.com/testimonials.php to read real quotes from published authors. 